\title{
Marangoni driven boundary layer flow past a flat plate in nanofluid with suction/injection
}

\begin{abstract}
The problem of Marangoni convection boundary layer flow past a flat plate in a nanofluid when the wall is permeable, where there is suction or injection effect, is studied using different types of nanoparticles. The general governing partial differential equations are transformed into a set of two nonlinear ordinary differential equations using unique similarity transformation. Numerical solutions of the similarity equations are obtained using the RungeKutta-Fehlberg (RKF) method. Three different types of nanoparticles, namely $\mathrm{Cu}, \mathrm{Al} 2 \mathrm{O} 3$ and $\mathrm{TiO} 2$ are considered by using water as a base fluid with Prandtl number Pr\#国.2. The effects of the suction or injection parameter on the flow and heat transfer characteristics are discussed.
\end{abstract}

Keyword: Boundary layer; Injection; Marangoni convection; Nanofluid; Suction 